\title{
ANÁLISE COMPARATIVA DA PROCESSUALIISTICA DOS ATOS INTERNACIONAIS NO MERCOSUL
}

\author{
Ticiana Noronha* \\ Fernando Kinoshita**
}

SUMÁRIO: Introđução. 2. Dos princípios aplicáveis pelas constituições. 3. Da competência do poder legislativo nos estados partes. 4. Da competência do poder executivo nos estados partes. 5. Conclusão. 6. Bibliografia.

SUMMARY: Introduction. 2. The Applicable Beginnings by the Constitutions. 3. The executive power's competence in the states of MERCOSUL. 4. Conclusion. 5. Bibliography.

SUMARIO: Introducción. 2. Los Principios Aplicables por las Constituciones. 3. La Competencia del Poder Ejecutivo en los Estados del MERCOSUL. 5. Conclusión. 6. Bibliografia.

RESUMO: $O$ artigo tem como objetivo confrontar as normas constitucionas que disciplinam a processualistica dos atos internacionais do MERCOSUL no sentido de definir quais são os entraves responsáveis pela demora entre a aprovação de um tratado internacional e a sua efetria aplicação, tanto externa quanto internamente A metodologia utilizada foi a hipotético-dedutiva. As conclusôes obtidas referem-se à supremacia irrestrita de que são dotadas, atualmente, as constituiçóes dos Estados Partes, bem como o processo para se chegar a uma harmonização das mesmas e a questão da criação de um Tribunal do MERCOSUL, dotado de autonomia nas decisões do MERCOSUL e mesma hierarquia que as constituiçoes dos Estados Partes.

\footnotetext{
*Acadêmica em Direito pela Universidade Federal de Santa Catarina - UFSC. Pesquisadora do Consetho Nacional de Pesquisa Cientifica - CNPq. E-mail: tcnoronhaOig.combr

$*$ Doutor em Direito Internacional e Comunitirio pela "Universidad Pontifina Comilas - UPCO - ICADE", Madri, Espanha e Professor de Direito Internacional Público na Universidade Federal de Santa Catarina - UFSC e-mail tradek0Ohotnaitcon
} 
ABSTRACT: The article has the purpose to compare Constitutional rules that instruct Processualistic of International Acts in a sense of defining what are the main hindrances that delay International Treaty approval and its effective aplications, both externally and internally. Didactic-hypothetic was the Methodology employed. The decisions achieved refer to an unlimited sovereignty that are currently endowed, the Constitutions of the Part-States, as well as the process to reach harmony with the same ones and the question of Mercosur-Court creation, with autonomy in decisions and same hierarchy as Part-States' Constitutions.

RESUMEN: El artículo tiene el propósito de comparar las reglas constitucionales que regulan la Processualística de actos internacionales en un sentido de definiendo cuáles son los obstáculos principales que retrasan la aprobación internacional del tratado y sus aplicaciones eficaces, externamente e internamente. La metodología empleada fue la Didáctico-hipotética. Las decisiones alcanzadas refieren a una soberanía ilimitada que se dotan actualmente, a las constituciones de los Parte-Estados, tan bien como el proceso para alcanzar armonía con las mismas y la cuestión de la creación de la Corte de MERCOSUR, con la autonomía sobre las decisiones de MERCOSUR y la misma jerarquía que las constituciones de los Parte-Estados tienen.

PALAVRASCHAVES: Direito de Integração. MERCOSUL. Direito Constitucional.

KEY-WORDS: Integration law. MERCOSUR. Constitucional Law.

PALABRAS-LLAVES: Derecho de Integración. MERCOSUR. Derecho Constitucional.

\section{Introdução}

No estágio em que se encontra a humanidade, a tendência atual é a união dos Estados afins mediante a cooperação internacional que em muitos casos reflete-se na consolidação de blocos econômicos ${ }^{1}$, buscando um fortalecimento mútuo.

A pesquisa ora efetuada, trata da processualística dos atos internacionais, em especial, os atos jurídicos derivados da crescente institucionalização jurídica do MERCOSUL, assunto de relevante importância tanto em nivel nacional quanto internacional. Tal pesquisa teve como ponto de concentração a análise de toda a legislação constitucional referente à processualística dos atos internacionais de cada Estado-Parte do MERCOSUL.

\footnotetext{
${ }^{1}$ Note-se que pcla evolução natural dos processos de integração $e$ de acordo com a teoria das uniões aduanciras, os processos de integração que num primeiro momento tenham um caráter eminentemente econômico podem gradualmente incorporar elementos políticos, sociais e culturais.
} 
O presente artigo está estruturado em três blocos de artigos afins das Constituições dos Estados Partes, o que possibilita ao leitor maior clareza na análise das semelhanças e diferenças dos artigos entre si.

Através da análise do Direito Internacional e Constitucional comparado efetuado, é possível estabelecer algumas ponderações relevantes que poderão auferir significativas mudanças nas relações internacionais, em especial no âmbito do MERCOSUL.

A primeira das ponderações refere-se à supremacia irrestrita de que são dotadas as normas constitucionais, problema que necessita de urgente solução, pois do contrário, não será possivel o estabelecimento de um Mercado Comum pleno. Corolário a essa questão, há que se passar à harmonização das constituições dos Estados Partes, a fim de promover um processo integracionista mais célere.

A segunda tem por objeto a eventual criação de um órgão supra-estatal, formado por representantes designados pelos Estados Partes, em igual número e com o mesmo poder de voto, independente da posição econômica ocupada por seu país, criando oportunamente, o Tribunal do MERCOSUL.

Esse Tribunal deve ser dotado de competência para se manifestar quanto às questóes de validade, vigência, interpretação e melhor aplicação das normas pertencentes ao MERCOSUL, buscando solucionar as controvérsias criadas entre os Estados Partes; entre as instituiçóes do MERCOSUL e/ou Estados Partes e particulares; entre os Estados Partes e particulares; e entre particulares pertencentes a diferentes Estados Partes.

Se a finalidade do MERCOSUL é transitar de uma União Aduaneira imperfeita (em que se constitui atualmente) para um Mercado Comum pleno, haveria que se contemplar a mudança dos procedimentos utilizados atualmente no âmbito das relações internacionais, tanto externa quanto internamente, a fim de proporcionar as evoluções que há tempos o mercado e a sociedade civil reivindicam.

Neste sentido, o presente artigo tem por objetivo estabelecer pontos de conexão entre as Constituições dos Estados Partes do MERCOSUL, através de um estudo comparado das normas que disciplinam a matéria, a fim de definir quais são os entraves responsáveis pela demora entre a aprovação de um tratado internacional e a sua efetiva aplicação, tanto externa quanto internamente.

Os incisos seguintes referem-se principios que são aplicados em cada constituição dos Estados Partes e sobre quem detém a competência para a efetuação dos atos internacionais. 


\section{Dos princípios aplicáveis pelas Constituições}

Mediante o Direito Constitucional comparado, podemos iniciar o estudo considerando o artigo 4 , da Constituição Brasileira quando estabelece que:

Art.4- A República Federativa do Brasil rege-se nas suas relações internacionais pelos seguintes princípios:

I - independência nacional;

II - prevalência dos direitos humanos;

III - autodeterminação dos povos;

IV - não-intervenção;

$\mathrm{V}$ - igualdade entre os Estados;

VI - defesa da paz;

VII - solução pacífica dos conflitos;

VIII - repúdio ao terrorismo e ao racismo;

IX - cooperação entre os povos para o progresso da humanidade;

$\mathrm{X}$ - concessão de asilo político.

Parágrafo único - A República Federativa do Brasil buscará a integração econômica, política, social e cultural dos povos da América Latina, visando à formação de uma comunidade latino-americana de nações.

Assim sendo, os princípios definidos por este artigo são relativos à comunidade internacional e visam traçar as diretrizes pelas quais se calcarão as atuações da República Federativa do Brasil com as demais nações.

A palavra princípio não comporta uma definição concreta, constituise em uma confluência de valores e bens que determinam as normas de conduta de uma nação específica. Portanto seu conteúdo essencial pode sofrer inúmeras variações, conforme os diferentes graus de valoração atribuídos aos bens, pessoas, fatos, preconceitos, enfim, aos acontecimentos da vida em cada sociedade.

A Constituição Brasileira e a Constituição Paraguaia assemelharamse muito na elaboração do artigo que trata dos princípios, inclusive no uso das mesmas palavras em muitos incisos. A forma de elencar os princípios um a um também restou equivalente, o que não ocorreu com as Constituições da Argentina e do Uruguai.

Os incisos com a mesma redação entre o artigo $4^{a}$ da Constituição Brasileira e o artigo 143 da Constituição Paraguaia são respectivamente: I e1; II e 5; III e 2; IV e 7; V e 3; sendo que os demais não fogem tanto à 
correspondência de sentido. Isto demonstra que é possível a harmonização das normas constitucionais dos Estados Partes, a fim de possibilitar a implantação de uma corte suprema internacional para deliberar sobre as negociações e tratados no âmbito do Mercosul.

Neste sentido, a Constituição Argentina determina em seu artigo 27 que: Art.27-O Governo Federal está obrigado a assegurar suas relações de paz e comércio com as potências estrangeiras por meio de tratados que estejam em conformidade com os princípios de direito público estabelecidos nesta Constituição ${ }^{2}$.

Esse artigo denota a supremacia da Constituição Argentina sobre os tratados estabelecidos com os outros países, ou seja, todos os tratados que não respeitarem os princípios de direito público contidos na Carta Maior, automaticamente, restarão ineficazes.

A Constituição Argentina, bem como as demais constituições dos Estados Partes, condicionam a validade dos tratados acordados entre si, à ratificação pelos membros do Congresso e posteriores tramites legais. Os procedimentos para a incorporação de um tratado às normas da Argentina correspondem a:

a) "A negociação e assinatura do tratado pelo Presidente da República (art. 99, 11);

b) A aprovação e recusa como função de controle, estão a cargo do Congresso (art.75, 22);

c) A ratificação do tratado, como função de convalidação, é um ato ulterior e independente do de sua aprovação e está a cargo do Executivo (art.31, in fine e art. 99, 11);

d) O tratado pode ser vetado, total ou parcialmente, nos mesmos termos previstos para a formação e sanção das leis (arts.80 e 83);

e) A publicação da ratificação deve ser feita em Jornal Oficial (art.83);

f) A troca das ratificações (nos tratados bilaterais) e o depósito de um certo número de ratificações (nos tratados multilaterais), é condição necessária para sua entrada em vigor;

g) A denúncia do tratado deve ser realizada através da intervenção do Congresso e/ou do Executivo, segundo os casos (art. 75, incisos 22 e 24), e de acordo com as regras da Convenção de Viena sobre o Direito dos Tratados".

Somente após todos esses tramites legais, restará aplicável no âmbito interno e externo o tratado firmado. Como se vê, o artigo 27 traz consigo a defesa da teoria dualista, sujeitando as normas de direito internacional à apreciação, a priori, pelos membros do Congresso, a fim analisar se há ou 
não agressão à Constituição da Argentina, para só então, aprovar ou recusar a incorporação do tratado às normas de direito interno do país.

Quiroga Lavié afirma que "los pueblos reivindican para sí la soberanía y la autodeterminación y no pueden desconocer que detrás de un argumento lógico puede encubrirse el poder efectivo de las potencias intrnacionales que determinan la creación del derecho internacional. Es por ello que siempre nos ha parecido conveniente mantener la plena vigencia de la supremacía de la Constituición sobre los tratados internacionales consagrada en el art. 27, lo cual no ha sido objeto de ninguna modificación en la reforma de 1994", corroborando, destarte, com a teoria dualista.

No entanto, sabe-se que a manutenção do texto constitucional da forma como está impede o avanço da doutrina internacional, ou seja, a prática efetivamente rápida e condizente com as necessidades do direito internacional, manifestadas por meio de seus tratados.

De certa forma, o autor não está totalmente errado, pois em matéria de direitos cogentes é sempre bom agir com cautela, principalmente os paises mais fracos (em termos econômicos, os ditos em desenvolvimento), todavia se o hourve a instituição do Mercosul (Tratado de Assunção) e os diversos compromissos que se firmaram mediante tratados posteriores, tendo como objetivo final a consolidação de um bloco econômico perfeitamente integrado, há que se promover a harmonização das constituições dos Estados Partes, a fim de agilizar as negociações realizadas, senão com todo o mundo, mas precipuamente e principalmente no âmbito do Mercosul.

A Constituição Uruguaia optou por estabelecer seus princípios dentro do contexto do artigo 6 , sem promover a citação dos mesmos em cada inciso, como fizeram as constituiçōes brasileira e paraguaia. Assim reza o citado artigo 6 da Constituição Uruguaia:

Art. 6 - Nos tratados internacionais que celebrados a República Uruguaia proporá a cláusula em que todas as diferenças surgidas entre as partes contratantes, serão decididas pela arbitragem ou outros meios paćficos A República procurará a integração social e econômica dos Estados Latino-americanos, especialmente no que se refere à defesa comum de seus produtos e matérias primas. Também proporá a efetiva complementação de seus serviços públicos. ${ }^{5}$

Procedendo-se ao exame, pode-se perceber que não houve disparidades entre os princípios elencados pela constituição Uruguaia e as demais.

Propôs ela o uso dos meios pacíficos para a solução dos conflitos surgidos;

+ Vid. OUIROGA, H. L. Constiución de la Nación Argentina Comentada. Argentina: Zavalia Editor, 1997, p. 150. Traduç̃o livre. 
a incessante busca pela integração social e econômica dos Estados Latino-Americanos. Todavia, a forma pela qual estruturou esse artigo deixou de ressaltar importantes princípios, os quais não se sabe se estão implícitos ou não, como é o caso da prevalência dos direitos humanos; e a autodeterminação dos povos.

Finalmente, a Constituição Paraguaia pertinentemente em seus artigos 141 e 143, conforme se observa a seguir:

Art. 141- Os tratados internacionais validamente celebrados, aprovados por lei do Congresso, e cujos instrumentos de ratificação foram trocados ou depositados, formam parte do ordenamento legal interno com a hierarquia que determina o artigo 137.

Art. 143- A República do Paraguai, em suas relações internacionais aceita o direito internacional e se ajusta aos seguintes princípios:

1-A independência nacional;

2-A autodeterminação dos povos;

3-A igualdade jurídica entre os Estados;

4-A solidariedade e a cooperação internacional;

5-A proteção internacional dos direitos humanos;

6-A livre navegação dos rios internacionais;

7-A não intervenção, e

8-A condenação de toda forma de ditadura, colonialismo e imperialismo. ${ }^{6}$

Como se ressaltou em análise supra, as semelhanças entre o artigo 143 da Constituição Paraguaia e o artigo $4^{\underline{a}}$ da Constituição Brasileira são enormes, o que demonstra a similitude de aspectos sócio-culturais entre os dois países, fato este de suma importância para a facilitação do estabelecimento de um bloco integrado entre os mesmos.

De fato, as semelhanças culturais, sociais, econômicas e políticas que detêm os países componentes do Mercosul, exerceu significativa influência para a consolidação do mesmo, não que isso seja condição sine qua non para a criação de um mercado comum, do contrário não se conceberia a existência da União Européia. Todavia, transportando-se para a América Latina, onde se situa o Mercosul, pode-se dizer que tais fatores foram importantes para a criação do mesmo.

Os tratados constituem-se em acordos celebrados entre Estados no intuito de ordenar suas relações recíprocas nos setores econômico, político, cultural, social, e assim por diante. Também existem tratados que versam sobre a resolução de determinado conflito, ou ainda, há àqueles dotados de intuito preventivo evitando, antecipadamente, certos atos ou prováveis situações conflituosas.

${ }^{6}$ Tradução livre. 
O artigo 141 da Constituição Paraguaia reforça a defesa da teoria dualista, pois submete a validade dos tratados à aprovação pelos membros do Congresso, bem como a troca dos instrumentos de ratificação nos acordos bilaterais, e o depósito nos acordos multilaterais.

Em sua parte final, faz referência ao artigo 137 da mesma, o qual versa sobre a hierarquia conferida às normas constitucionais, aos tratados, convênios, acordos internacionais, as leis e outras disposições juridicas, ressaltando a supremacia das normas constitucionais sobre todas as outras.

\section{Da competência do poder legislativo nos Estados Partes}

Uma vez considerados os princípios constitucionais dos Estados partes relativos às suas relações internacionais, passa-se à análise da competência do Poder Legislativo em cada Estado Parte e que tem um papel altamente importante na incorporação de normas internacionais. De acordo com a Constituição Brasileira, em seu artigo 49, a mesma esclarece que: Art.49- E da competência exclusiva do Congresso Nacional:

I - resolver definitivamente sobre tratados, acordos ou atos internacionais que acarretem encargos ou compromissos gravosos ao patrimônio nacional;

Depreende-se da análise de tal artigo, a vontade que teve o legislador em frisar que a competência para solucionar quaisquer questões pertinentes a tratados, acordos ou outro atos internacionais, pelos quais o Brasil tenha a possibilidade de ser responsabilizado, onerando, assim, o patrimônio nacional, cabe com exclusividade ao Congresso Nacional.

Portanto o fato de o Presidente da República, bem como por agentes munidos de carta de plenos poderes, representando a sua pessoa, assinar tratados, acordos ou convençōes internacionais, não faz desses instrumentos auto-aplicáveis.

Faz-se necessária, e de competência exclusiva do Congresso Nacional, promover a análise de qualquer tratado internacional acordado entre o Brasil e outro Estado, seja este pertencente ao MERCOSUL ou não.

Há quem sustente o desnecessário referendamento de todo ato internacional pelo Congresso, argumentando que a prática de tal mandamento acarretaria uma burocracia demasiada, promovendo, por conseguinte, uma sobrecarga de trabalho, o que fatalmente provocaria a uma lentidão nos trâmites relacionados aos atos internacionais, contrariando, assim, a agilidade dos mesmos. 
Os procedimentos cabiveis para a entrada em vigor de um tratado internacional internamente no Brasil não se restringem a sua aprovação pelo Congresso Nacional (Câmara e Senado), é preciso realizar a sua oficialização através de decreto legislativo devidamente publicado no Diário Oficial da União, desacompanhado do texto do ato internacional.

Todavia tal publicação também não é sinônimo de reconhecimento da incorporação interna imediata do referido instrumento, mas apenas a expressão da aceitação dos seus termos.

Vale lembrar que os membros do parlamento estão impedidos de promover alterações no texto do tratado, pois este é ato privativo do Presidente da República (art.49, I), entretanto podem eles sugerir alguma alteração.

Para alcançar a vigência externa e interna há que se proceder de maneiras diversas. A primeira consubstancia-se através da ratificação do acordo internacional exercida pelo Poder Executivo do Brasil, estando este previamente autorizado pelo Congresso Nacional, por meio da troca dos instrumentos de ratificação (tratados bilaterais) ou depósito dos mesmos (sendo tratados multilaterais).

No que tange à vigência interna, esta só passará a existir após a promulgação exercida através de decreto do Presidente da República, o qual é publicado no Diário Oficial da União, desta vez acompanhado do texto do ato internacional.

A partir desse momento o ato torna-se público, e conseqüentemente, obrigatório no âmbito interno do Brasil. Por outro lado, o entendimento constitucional na Argentina, segundo seu artigo 75, é no sentido de que: Art.75-Corresponde ao Congresso:

XXII - Aprovar ou desfazer tratados concluídos com as demais naçóes e com as organizações internacionais e os tratados com a Santa Sé. Os tratados dos Estados entre si e os efetuados entre a Santa Sé e a Argentina têm hierarquia superior às leis.(...) Os demais tratados e convençôes sobre direitos humanos, requererão, para serem aprovados pelo Congresso de dois terços dos votos de todos os membros de cada Câmara para gozar de hierarquia constitucional.

XXIV - Aprovar tratados de integração que deleguem competências e jurisdição a organizações supra-estatais em condições de reciprocidade e igualdade, e que respeitem a ordem democrática e os direitos humanos. As normas ditadas em consequiencia têm hierarquia superior às leis.

A aprovação destes tratados com Estados latino-americanos requererá a 
maioria absoluta da totalidade dos membros de cada Câmara. No caso de tratados com outros Estados, o Congresso da Nação, com a maioria absoluta dos membros presentes de cada Câmara, declarará a conveniência da aprovação do tratado e somente poderá ser aprovado com o voto da maioria absoluta da totalidade dos membros de cada Câmara, depois de cento e vinte dias do ato declarativo.

A denúncia dos tratados referidos a este inciso, exigirá a prévia aprovação da maioria absoluta da totalidade dos membros de cada Câmara.?

$\mathrm{O}$ artigo 75 da Constituição Argentina representa uma grande evolução nos trâmites relacionados ao Direito Internacional, especialmente no que tange ao MERCOSUL.

Em seu inciso XXII, estabelece a competência ao Congresso em aprovar ou desfazer tratados concluídos com outras nações, com organizações internacionais e com a Santa $S e ́$, mas a parte mais significativa deste inciso e que estabeleceu novo paradigma dentro das relações internacionais, dando impulso significativo ao MERCOSUL, foi a colocação dos tratados e acordos internacionais num patamar hierárquico superior às próprias leis do país.

Esse era o primeiro passo que deveria ser dado, a fim de que a Argentina pudesse integrar-se aos novos valores que estavam sendo criados, ou seja, que ela adquirisse a capacidade de participar efetivamente dos novos blocos econômicos que estavam surgindo, pois se as próprias leis do país viessem a derrogar os tratados internacionais previamente acordados, tornar-se-ia impossivel estabelecer um mercado comum sério.

Afinal de que vale movimentar toda uma "máquina" de representantes dos Estados Partes, os quais após a realização dos diversos procedimentos exigidos para a formulação e aprovação de um tratado, terão por ineficaz tais atos quando da derrogação do tratado por uma lei interna mais recente.

Por isso a importância desse artigo que coloca os tratados e acordos internacionais em um patamar hierárquico superior às leis internas da Argentina, todavia tal patamar ainda se encontra em posição inferior à legislação constitucional da mesma. Isso está colocado expressamente no inciso XXII, do artigo 75, que dispõe in verbis: "Los tratados y concordatos tienen jerarquía superior a las leyes."

A questão referente à supremacia dos tratados em relação às leis internas de cada país é pedra fundamental para a criação e vigência adequada dos mesmos; já o que causa discussões doutrinárias e o conseqüente 
surgimento de opiniões díspares entre os juristas é o fato de saber se os tratados devem ter ou não hierarquia superior à Constituição de cada Estado-Parte.

$\mathrm{Na}$ Constituição Argentina existem dez $\mathrm{z}^{8}$ tratados internacionais (cinco gerais, dois contra a discriminação, um contra o genocídio, um contra a tortura e um sobre os direitos da criança) que possuem hierarquia igualada à mesma, sendo que todos eles tratam de questões relativas aos direitos humanos (artigo 75, XXII).

Daí surge a questão: por que conceder tal grau de hierarquia somente a esses tratados? Se o intuito do MERCOSUL é (a longo prazo) tornarse um mercado comum, a semelhança da União Européia, onde há união aduaneira, livre circulação dos fatores de produção: capital e trabalho, ou seja, a livre prestação de serviços profissionais pelos membros de qualquer Estado-Parte, urge um novo contexto constitucional, o qual possibilite uma abertura gradual, conferindo, "a priori" a igualdade hierárquica entre as normas constitucionais e os tratados internacionais realizados no âmbito do MERCOSUL.

Tal igualdade faria com que desaparecesse a necessidade de prévia ratificação por parte do Congresso, para a posterior incorporação dos tratados acordados entre os Estados Partes no ordenamento jurídico de cada país membro, tornando-os auto-aplicáveis.

Isso representaria maior agilidade na tomada de soluções e, conseqüentemente, maior eficácia nas transações estabelecidas, pois desapareceriam todos os debates demorados e "intermináveis" realizados entre os congressistas quando da análise de possíveis conflitos entre as normas e princípios da Constituição de seus países e os tratados internacionais acordados.

Destarte, haveria um aprofundamento no processo de integração, fazendo com que o MERCOSUL evoluísse para um estágio mais próximo ao Direito Comunitário, o qual possui superioridade hierárquica, aceitação imediata pelos ordenamentos jurídicos de cada país membro e auto-aplicabilidade (adotado na União Européia).

Atualmente o MERCOSUL adota o Direito de Cooperação sendo a sua natureza de Direito Internacional Público, nesse caso, não há um direito supranacional auto-aplicável, como ocorre no Direito Comunitário.

Ainda no artigo 75, em seu inciso XXIV constata-se a clareza com que

\footnotetext{
O Congresso incorporou o décimo primeiro tratado internacional sobre direitos humanos com hierarquia constitucional através da Lei 24820, trata-se da Convenção Interamericana sobre Desaparição Forçada de Pessoas aprovada pela OEA em sua vigésima quarta Assembléia Geral.
} 
expõe a Argentina sua delegação, apenas em relação à competência e a jurisdição, às organizaçôes supra-estatais e não no que se refere à soberania nacional.

Estabelecer tal diferença é de suma importância, pois do contrário estar-se-ía criando possibilidades para que organizações supra-estatais fizessem uso desse artigo criando normas ou regimes que estivessem em contradição com a Constituição Argentina. Seria como deixar o país, a mercê do controle e vontades externos.

A Argentina pode delegar competências e jurisdição a órgãos supraestatais, como afirma o inciso XXIV do artigo 75 , todavia o exercício das mesmas estará submetido a um controle jurisdicional de constitucionalidade exercido pela própria, ou seja, a Argentina reconhece a existência de órgãos supra-estatais, mas não se coloca em um patamar de inferioridade hierárquica em relação aos mesmos, assumindo uma posição de igualdade, e tomando parte nas decisōes elaboradas por eles, ainda que não os integre.

Cumpre destacar que tal delegação deve ocorrer em condiçóes de igualdade e reciprocidade com os demais Estados Partes e que respeitem a ordem democrática e os direitos humanos, isto é, a Argentina, mesmo sem integrar os organismos supra-estatais, impôs, através desse inciso, seu poder de opinar e verificar se não há ofensas à sua Carta Magna nas decisões prolatadas por tais organismos.

Tocante à segunda cláusula do inciso XXIV, percebe-se que os constituintes argentinos estipulam diferenças favoráveis nos procedimentos para a aprovação de tratados com os Estados Latino americanos em comparação aos demais.

A diferença encontra-se na exigência de trâmites mais complexos e dificeis de cumprir, estabelecendo uma semi-rigidez implicita em sua for$\mathrm{ma}$, agindo com mais cautela quando da análise das decisões de organismos supra-estatais, a fim de não ferir sua Constituição, mesmo porque as relações mantidas entre países em desenvolvimento com os países ricos, ditos do "primeiro mundo" são eivadas de um sentimento de desconfiança, pelos países menos afortunados, pois estes sabem que aqueles têm sempre interesses escusos visando apenas auferir um beneficio próprio. 
Por isso a mantença de relações internacionais faz-se mais real entre países parecidos, próximos ou pelo menos com um vínculo forte entre eles, um vínculo capaz de superar as diferenças, as quais se sabe serem muitas de país para país, cidadão para cidadão, a fim de alcançar a solidez de um mercado comum eficiente, capaz de trazer benéfices aos seus integrantes, fortalecendo-os contra a exploração econômica dos países mais poderosos.

Se foi possivel a criação da União Européia, mesmo com todas as diferenças existentes de culturas, línguas, crenças e raças, em favor do fator econômico, o vínculo existente, por que não seria possível o estabelecimento de um mercado comum efetivo no MERCOSUL já que as afinidades são maiores e em toda a América Latina.

Enquanto na União Européia o vínculo que possibilita a união das nações é o fator econômico, aqui na América Latina tal fator é o responsável, ao mesmo tempo, pela integração, que pode ser observada no MERCOSUL; mas também como motivo de demora no aperfeiçoamento de suas relações, pois a desestabilidade econômica dos países latinos faz com que a sua credibilidade para integrar o MERCOSUL seja diminuída.

Já houve exemplos de tentativas de integração mal sucedidas (Associação Latino-Americana de Livre Comércio e Associação Latino-Americana de Integração), nas quais os determinantes do insucesso foram a pseudoconcorrência e a estipulação dos países integrantes de barreiras protecionistas em suas economias, visando proteger interesses internos de cada país, sem pensar nas intenções do grupo. Daí o seu insucesso.

Finalmente, a terceira cláusula dispõe sobre a possibilidade de denúncia dos tratados pela nação argentina, tanto em virtude de razões políticas, quanto por inconstitucionalidade. A iniciativa em denunciar pode ser do Poder Executivo ou do Congresso.

Quanto do Uruguai, ao Poder Legislativo da República Oriental é assegurado em seu artigo 85 o seguinte:

Art. 85-Compete à Assembléia Geral:

7- Decretar a guerra e aprovar ou reprovar por maioria absoluta de votos do total de componentes de cada Câmara, os tratados de paz, aliança, comércio e as convençóes ou tratados de qualquer natureza que celebre o Poder Executivo com as potências estrangeiras.

20- Concluir e assinar tratados, necessitando para ratificá-los a aprovação do Poder Legislativo ${ }^{10}$. 
A Constituição Uruguaia, assim como a brasileira, foi rígida ao formular suas normas referentes ao processo de aprovação de tratados, não apresentando qualquer tipo de flexibilização, como ocorreu nas constituiçôes Paraguaia e Argentina.

Dessa forma, o artigo 85, em seu inciso 7 determina a necessidade de aprovação dos tratados internacionais celebrados pelo representante do Poder Executivo, pela maioria absoluta dos votos do total dos componentes de cada uma das Câmaras (deputados e senadores).

Ainda em seu artigo 85, inciso 20, denota a competência da Assembléia Geral para a conclusão e assinatura dos tratados internacionais, na dependência da prévia aprovação por parte do Poder Legislativo, para promover a ratificação.

Neste sentido a Constituição Paraguaia, em seu artigo 202 determina que: Art.202- São deveres e atribuições do Congresso:

IX - aprovar ou recusar os tratados e demais acordos internacionais assinados pelo Poder Executivo ${ }^{11}$.

$\mathrm{O}$ artigo 202, em seu inciso nove determina ser dever do Congresso aprovar ou recusar os tratados e demais acordos assinados pelo Poder Executivo.

A Constituição Paraguaia, assim como as demais constituições dos Estados Partes, foram uníssonas neste ponto, delegando competência para a ratificação dos tratados, convenções e acordos internacionais ao Congresso, sendo que, somente após sua prévia apreciação e concordância (mediante ratificação) em cada país, os referidos documentos entrarão em vigor no âmbito externo dos Estados Partes.

Todo este processo realizado para a "homologação" do tratados, acordos e convenções internacionais tem sua razão precípua, qual seja, a manutenção da supremacia das normas emanadas pela Constituição de cada Estado-Parte.

Por isso, faz-se necessária prévia análise de cada tratado, acordo e convenção firmado entre os Estados Partes, à luz do saber jurídico dos congressistas, a fim de que o disposto em seus artigos não vá de encontro às Cartas Magnas de cada país, ofendendo destarte a soberania interna nacional.

\section{Da competência do poder executivo nos Estados Partes}

Agregando-se aos princípios constitucionais e às competências do Poder Legislativo, o Poder Executivo desempenha atribuições de fundamental importância no estudo da processualística dos atos internacionais derivados do MERCOSUL. 
Assim sendo, a Constituição da República Federativa do Brasil estabelece em seu artigo 84 que:

Art.84-Compete privativamente ao Presidente da República:

VIII- celebrar tratados, convençóes e atos internacionais, sujeitos a referendo do Congresso Nacional;

Esse inciso estabelece como competencia exclusiva do Presidente da República o poder de celebrar tratados, convenções e atos internacionais, reforçando o que já afirmava o artigo 49 acima analisado, ou seja, que tais atos dependem de prévia aprovação por mais da metade dos membros do Congresso Nacional.

É claro que na impossibilidade do Presidente assinar os tratados, estes podem ser firmados por pessoas acreditadas por ele, geralmente Ministro das Relações Exteriores ou diplomatas.

Pelo que se refere à competência do Poder Executivo Argentino, a Constituição de nosso maior associado sul-americano reza em seu artigo 99 que:

Art99-O presidente da Nação tem as seguintes atrïbuições:

11-Conclui e firma tratados com outros Estados, tratados, acordos e outras negociações requeridas para o mantimento de boas relações com as organizações internacionais e as nações estrangeiras, recebe seus ministros e admite seus cônsules ${ }^{22}$.

Antes da reforma constitucional de 1994, havia uma enumeração das classes dos tratados, dispondo sobre aqueles que o Presidente podia assinar.

Após a reforma, tal disposição foi suprimida, colocando todos os tratados internacionais sob o crivo do Presidente da República, isso demonstra uma fática elucidação da lei, evitando maiores divergências interpretativas, pois como bem afirma Quiroga Lavié, "isso já acontecia na prática" "

A competencia auferida ao Presidente para a assinatura dos tratados não poderá ser destituída, pois ele é o chefe do Estado e a ele cabe manter relações politicas, e de interesse para o seu país com os demais Estados. Todavia, o Congresso pode não concordar com os atos aprovados pelo Presidente, achando que os mesmos causam prejuízo ao Estado, ou ain$\mathrm{da}$, que ferem os dispositivos constitucionais.

Nesse caso, cabe ao Congresso não aprová-los, ou seja, não conceder a ratificação do ato presidencial, fazendo com que o tratado assinado pelo Presidente não tenha vigência externa, nem interna. A Justiça, em casos espećficos de aplicação, também poderá exercer o controle de constitucionalidade.

Ressalta-se a desnecessidade de ratificação pelo Congresso Nacional, dos chamados acordos executivos, os quais "em tese" versam somente

is Traducato livre.

1. Va. QUROGA, H. L. Constitución de la Nacion Argentina Comentada Argentina: Zavalia Editor, 1997, p. 615 . 
sobre matérias administrativas, como por exemplo: notas reversais, acordos em forma simplificada e os protocolos.

Não concordamos com essa atitude, pois não cabe somente ao presidente determinar, por força de sua própria razão, o que é certo ou errado, melhor ou pior para o Estado, há que se ter, também, a opinião dos representantes do povo, a fim de melhor resguardar os principios constitucionais e os interesses da nação.

Assim como não lhe é permitido estabelecer decretos com força de lei, muito menos o será aprovar tratados que comprometam o país perante os outros Estados. Quanto ao Uruguai, sua Constituição determina que: Art.159-O presidente da República representará o Estado no interior e no exterior. Art. 168-Ao presidente da República, atuando com o Ministro ou Ministros respectivos ou com o Conselho de Ministros corresponde:

15- Receber agentes diplomáticos e autorizar o exercício de suas funçöes aos Cônsules estrangeiros.

20- Concluir e assinar tratados, necessitando para ratifica-los a aprovação do Poder Legislativo ${ }^{14}$.

O artigo 159 estabelece ao Presidente da República a função de representar o Estado interna e externamente.

E o artigo 168, em seu inciso 15, especifica a atividade do Presidente, o qual juntamente com o Ministro ou o Conselho de Ministros deverá receber e conceder autorização aos diplomatas para o exercicio de suas atividades dentro do país.

Ainda no artigo 168, mas em seu inciso 20, a Constituição Uruguaia tratou expressamente da competência cabível ao Presidente da República para firmar tratados com os demais Estados, no entanto, estabeleceu como condição para a sua vigência e validade a ratificação pelo Congresso Nacional.

Finalmente a Constituiçäo Paraguaia estabelece o seguinte em seu artigo 238: Art.238-São deveres e atribuições de quem exerce a presidência da República: 7-dirigir o manejo das relaçôes exteriores da República. Em caso de agressäo externa, e previa autorização do Congresso, declarar o Estado de Defesa Nacional ou concentrar a paz; negociar e firmar tratados internacionais; receber aos chefes de missões diplomáticas dos países estrangeiros e admitir a seus cônsules; e designar embaixadores, com aprovação do Senado;

Esse inciso institui expressamente ao Presidente da República o poder de dirigir, negociar e assinar tratados internacionais.

Ademais, confere ao mesmo a função de receber os diplomatas dos outros Estados e admiti-los a seus cônsules; bem como designar embaixadores, sempre com a prévia aprovação dos membros do Senado.

39 Traduça livre. 


\section{Conclusão}

A sociedade mundial passa, atualmente por uma série de transformaçôes, as quais revelam a necessidade de união entre os Estados consolidando os mercados, no intuito de maior fortalecimento econômico e lucros. Isto evidencia uma nova era, que traz reflexos importantes no mundo jurídico, o qual deixa de se restringir ao direito interno e abre caminhos para o direito internacional.

Todavia, tal mudança de foco não se dá de maneira fácil e flexível, pois o direito interno, tendo em vista o maior espaço de tempo em que vigora, já tem traçados certos paradigmas, os quais não pretende mudar, e justamente nestes paradigmas é que se encontram os problemas que o direito internacional precisa suplantar para seu perfeito desenvolvimento.

O principal e maior paradigma, que precisa ser suplantado pelo direito internacional, é a questão referente à supremacia irrestrita das normas constitucionais de cada Estado-Parte, o que dificulta muito a aprovação e efetiva aplicação dos tratados internacionais.

O presente artigo trouxe uma comparação entre as principais normas contidas nas constituições dos Estados Partes relacionadas às atuaçôes do direito internacional e como se dá a dinâmica da sua processualística, tendo em destaque o MERCOSUL. Diante de tal análise pôde-se tirar algumas conclusões bastante significativas para uma verdadeira evolução e revolução nas relações internacionais do MERCOSUL.

Denota-se a abertura promovida pelas Constituições da Argentina e do Paraguai, que em suas recentes reformas promoveram modificações significativas prevendo e autorizando a eficácia das decisões tomadas pela cúpula do MERCOSUL em seus ordenamentos juridicos internos, sem ter que ser submetidas à análise e aprovação dos membros do Congresso.

Já o Brasil, ao invés de seguir o exemplo da Argentina e do Paraguai, consolidando o MERCOSUL, e tornando a aprovação dos tratados mais ágeis, optou por burocratizar ainda mais as negociações, delegando ao Supremo Tribunal Federal o poder de declarar, de pronto, a inconstitucionalidade de qualquer decisão proveniente da cúpula do MERCOSUL sem antes ter sido aprovada pelo Congresso Nacional.

O Uruguai seguiu a mesma linha do Brasil, visto que em sua Carta Magna, não há referência de aberturas na aprovação de tratados vindos dos órgãos supra-estatais, sem antes passar pela aprovação dos membros da Assembléia Geral.

O MERCOSUL, a exemplo da União Européia, deveria ser dotado de um Tribunal próprio, que fizesse coisa julgada nas questões internacionais de sua competência, sem precisar delegar tais decisōes a órgãos 
jurisdicionais dos Estados Partes, assim haveria um só entendimento, o qual seria aceito por todos os membros do bloco econômico, e não existiria riscos de pareceres diferentes de um Estado-Parte para o outro.

Infelizmente isso ainda não é possível, em virtude das legislaçōes (constituições dos Estados Partes), as quais tolhem tal atitude no MERCOSUL. É preciso mudar essa concepção fechada frente às novas solicitações do MERCOSUL, pois se o desejo dos Estados Partes é tornarem-se um mercado comum integrado, faz-se indispensável a criação de um Tribunal do MERCOSUL, dotado de competência para se manifestar quanto a questão da validade, vigência, interpretação e melhor aplicação das normas pertencentes ao MERCOSUL, na busca de solucionar as controvérsias criadas entre os Estados Partes uns com os outros; entre os Estados Partes e particulares; e entre particulares pertencentes a diferentes Estados Partes.

Depreende-se da confrontação e análise dos artigos referentes à competência para firmar tratados internacionais, auferida ao Presidente dos respectivos Estados, a situação de que, apesar do chefe do Estado (ou seu acreditado) participar do estudo e aprovação dos tratados, dando sua assinatura como garantia de aceitação pelo país dos termos constantes no acordo, tal ato de nada vale, pois tanto para conseguir a vigência interna, quanto externa é necessária a ratificação do ato pelo Congresso de cada país.

Isso representa um entrave ao perfeito desenvolvimento do Direito Internacional, e em conseqüência, proporciona morosidade no andamento das negociações internacionais.

Para o MERCOSUL, que ainda se encontra nos primeiros passos, tal fato insurge-se como um obstáculo no perfeito caminhar, desacreditando as negociações e planos futuros de integração mais completa.

É certo que deve haver um respeito à soberania de cada. Estado-Parte, afinal, cada país tem seu interesse próprio, e dentro do sistema capitalista em que esta inserido, visa proteger sua riqueza, obtendo maior lucro.

Todavia, não há como constituir um mercado comum, se não houver uma cessão de soberania de cada Estado-Parte, semelhante ao que ocorreu ao cidadão, quando da instituição do Estado.

É a retomada do velho contratualismo pelo qual o Estado formou-se através de um pacto: o contrato social, que proporcionou aos indivíduos saírem do estado de natureza (onde cada um era por si, era a lei do "matar ou morrer") e se tornarem cidadãos sociáveis vivendo segundo as regras estipuladas pelo, então formado, Estado. Após a constituição do Estado os indivíduos nảo mais possuíam suas liberdades por inteiro, mas haviam cedido parte da mesma, a fim de constituir o Estado de direito, deixando para o passado o Estado de natureza. 
Assim também deve ser a formação do MERCOSUL, pois se o desejo é transitar de uma União Aduaneira imperfeita (em que se constitui atualmente o MERCOSUL) para um Mercado Comum efetivamente integrado, há que se contemplar, a necessidade de transformar os procedimentos efetuados atualmente para a vigência interna e externa dos tratados acordados em nível de MERCOSUL, criando um sistema supranacional, dotado de órgãos supra-estatais, constituindo, assim, um Tribunal Internacional.

Não se trata de criar um órgão supra-estatal autoritário, em que as decisões sejam proferidas sem a participação e anuência dos Estados Partes, mas sim, de promover o surgimento de um órgão supra-estatal participativo, colocando os Estados Partes num mesmo patamar hierárquico, independente da renda econômica de cada um, pois do contrário, iriam começar a surgir pequenos privilégios e a integração restaria partida.

\section{BIBLIOGRAFIA}

ACCIOLY, Hildebrando \& SILVA, Geraldo Eulálio do Nascimento e. Solução pacífica de litígios internacionais. In: - Manual de Direito Internacional Público. São Paulo: Saraiva, 1998. 13ed. p. 429-60.

ARAUJO, Nadia de; SALLES, Carlos Alberto de \& ALMEIDA, Ricardo R. Cooperação interjurisdicional no Mercosul. In: BASSO, Maristela (org.). Mercosul: seus efeitos jurídicos, econômicos e políticos nos estados-membros. Porto Alegre: Liv. Advogado, 1995. p. 339-69.

BATISTA, Luiz Olavo. Solução de divergências no Mercosul. In: BASSO, Maristela (org.). Mercosul: seus efeitos jứídicos, econômicos e políticos nos estados-membros. Porto Alegre: Liv. Advogado, 1995. p. 91-115.

BASTOS, Carlos Eduardo Caputo. O processo de integração do Mercosul e a questão da hierarquia constitucional dos tratados. Brasília: Senado Federal, Assoc. Bras. de Estudos da Integração; 1997. (Estudos da Integração, $12^{\mathrm{a}}$ v.).

CASELLA, Paulo Borba. O tribunal: mecanismos de solução de controvérsias, interpretação e aplicação das normas comuns e controle da legalidade dos atos da administração. In: —- Mercosul: exigências e perspectivas. São Paulo: LTr, 1996. cap. vii, p. 164-78.

CASELLA, Paulo Borba. Normas supranacionais e divisão de competência entre instituiçôes nacionais e comuns. In: - Mercosul: exigências e perspectivas. São Paulo: LTr, 1996. cap. x, p. 228-43.

COSTA, José Augusto Fontoura. Aplicabilidade direta do direito supranacional. In: CASELLA, Paulo Borba (coord.). Contratos internacionais e Direito Econômico no Mercosul. São Paulo: LTr, 1996. p. 141-62. 
FRAGA, Mirtô. O conflito entre tratado internacional e norma de direito interno. Rio de Janeiro: Forense, 1997.

FREITAS, Ruben Correa. Derecho Constitucional Contemporaneo. Uruguay: Fundación de Cultura Universitaria, 1993. T. I. p.53-66.

GARCIA JR., Armando Alvares. Conflito entre normas do Mercosul e direito interno. São Paulo: LTr, 1997.

GOULENE, Alain. Supranacionalidade da Justiça: efetividade da integração econômica regional e proteção dos direitos subjetivos. In: CASELLA, Paulo Borba (coord.). Contratos internacionais e Direito Econômico no Mercosul. São Paulo: LTr, 1996. p. 308-47.

GREBLER, Eduardo. A solução de controvérsias no Tratado do Mercosul. In: CASELLA, Paulo Borba (coord.). Contratos internacionais e Direito Econôtnico no Mercosul. São Paulo: LTr, 1996. p. 348-362.

GUIMARÃES, M. A. Miranda. Conflitos de leis, de jurisdição e de jurisprudência. In: - Concorrências e licitações no Mercosul. Porto Alegre: Liv. Advogado, 1997. c. I, p. 13-21.

KINOSHITA, Femando. A Ação Exterior do Mercosul: Dez anos de Triunfos In: Carta Internacional. São Paulo: USP/NUPRI, Vol. 98,2001, p. 44. KINOSHITA, Fernando. Direito Internacional da Cooperação: A Zona de Livre Comércio entre o Mercosul e a União Européia. Rio de Janeiro: Papel \& Virtual, 2001.

KINOSHITA, Fernando. Manual Bibliográfico e de Pesquisa das Relações entre o Mercosul e a União Européia: Documentos Impressos e Eletrônicos. Rio de Janeiro: Papel \& Virtual, 2001.

KINOSHITA, Fernando. Mercosur y Unión Europea: De la Cooperación al Libre Comercio. Rio de Janeiro: Papel \& Virtual, 2001.

KLAES, Marianna Izabel Medeiros. Supranacionalidade: Paradigma necessário ao Mercosul. Florianópolis: Dissertação de Mestrado, 1999.

MACHADO, Patrícia Ferreira. A Constituição e os Tratados Internacionais. Rio de Janeiro: Forense Universitária, 1999.

MELO, Adriane Cláudia. Supranacionalidade e intergovernamentabilidade no Mercosul. In: ILHA, Adayr da Silva \& VENTURA, Deisy (org.). O Mercosul em Movimento II. Porto Alegre: Liv. Advogado, 1999. p.13-35. MEDEIROS, Antônio Paulo Cachapuz de. O poder de celebrar tratados. Porto Alegre: S. Fabris, 1995.

MERCADANTE, Araminta de Azevedo. A processualística dos atos internacionais: Constituição de 1988 e Mercosul. In: CASELLA, Paulo Borba (coord.). Contratos internacionais e Direito Econômico no Mercosul. São Paulo: LTr, 1996. p. 458-505. 
PANGRAZIO, Miguel Angel. Tratado de Derecho Público. Asunción: Ediciones y Arte S.R.L., 1996. 830p.

PIZZOLO, Calogero. Pensar el Mercosur. Argentina: Ediciones Jurídicas Cuyo, 1998.

QUIROGA, Humberto Lavié. Constituición de la Nación Argentina Comentada. Argentina: Zavalia Editor, 1997. 754p.

RANGEL, Vicente Marotta. Solução de controvérsias após Ouro Preto. In: CASELLA, Paulo Borba (coord.). Contratos internacionais e Direito Econômico no Mercosul. São Paulo: LTr, 1996. p. 692-701.

RODRIGUES, Horácio Wanderlei (org.). Solução de controvérsias no Mercosul. Porto Alegre: Liv. Advogado, 1997.

ROSA, Luis Fernando Franceschini da. Mercosul e função judicial. São Paulo: LTr, 1997.

SALLES, Carlos Alberto de. A cooperação interjurisdicional no Mercosul. In: CASELLA, Paulo Borba (coord.). Contratos internacionais e Direito Econômico no Mercosul. São Paulo: LTr, 1996. p. 721-37.

VENTURA, Deisy de Freitas Lima. A Ordem Jurídica do Mercosul. Porto Alegre: Livraria do Advogado, 1996. 